\title{
The Da Silva cone operation after the Starnes procedure for Ebstein's anomaly: New surgical strategy and initial results
}

\author{
Jose Pedro Da Silva, MD, Melita Viegas, MD, Mario Castro-Medina, MD, and \\ Luciana Da Fonseca Da Silva, MD, Pittsburgh, Pa
}

\footnotetext{
From the Department of Cardiothoracic Surgery, UPMC Children's Hospital of Pittsburgh, Heart Institute, University of Pittsburgh Medical Center, Pittsburgh, Pa.

Disclosures: The authors reported no conflicts of interest.

The Journal policy requires editors and reviewers to disclose conflicts of interest and to decline handling or reviewing manuscripts for which they may have a conflict of interest. The editors and reviewers of this article have no conflicts of interest.

Received for publication April 7, 2020; revisions received April 7, 2020; accepted for publication May 8, 2020; available ahead of print May 17, 2020.

Address for reprints: Jose Pedro Da Silva, MD, Cardiothoracic Surgery, UPMC Children's Hospital of Pittsburgh, Faculty Pavilion, 5th Floor, 4401 Penn Ave, Pittsburgh, PA 15224 (E-mail: dasilvajp@upmc.edu).

JTCVS Techniques 2020;3:281-3

2666-2507

Copyright (C) 2020 The Authors. Published by Elsevier Inc. on behalf of The American Association for Thoracic Surgery. This is an open access article under the CC BY-NC-ND license (http://creativecommons.org/licenses/bync-nd/4.0/).

https://doi.org/10.1016/j.xjtc.2020.05.011
}

Video clip is available online.

Neonates with severe Ebstein's anomaly (EA) represent a surgical challenge. The Starnes procedure has been used as effective surgical palliation for these critically ill patients. ${ }^{1}$ This strategy decompresses the right ventricle, allowing the left ventricle to assume a globular shape, improving function. ${ }^{2}$ Kumar and associates ${ }^{3}$ reported mid-term survival of $81 \%$ at 10 years by committing patients to the single-ventricle pathway after the Starnes procedure. ${ }^{3}$ However, this strategy exposes these patients to long-term complications associated with Fontan palliation.

Instead, we pursued the long-term benefits of the 2ventricle circulation, reactivating the right ventricle after the Starnes procedure using the cone repair technique. Here we describe our initial experience with this new approach.

\section{METHODS}

\section{Patients}

As of May 2019, 2 patients with severe EA and pulmonary atresia who underwent a neonatal Starnes procedure followed a 1-1/2- or 2-ventricle repair strategy. The patients' parents provided signed consent for publication of the medical data.

Patient 1 was a 3-kg full-term neonate who initially received a BlalockTaussig shunt. Extracorporeal membrane oxygenation (ECMO) support was required to manage low cardiac output. The next day, she underwent a Starnes procedure with cryoablation of the Wolff-Parkinson-White pathways. One day later, ECMO support was discontinued. At 4 months, she underwent a bidirectional Glenn procedure with pulmonary valvotomy. valvoplasty.

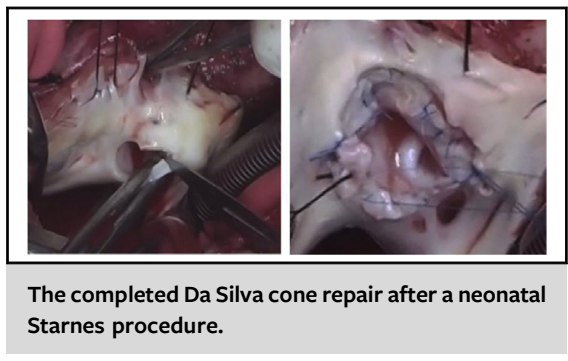

\begin{abstract}
CENTRAL MESSAGE
Tricuspid valve repair using the cone technique after a neonatal Starnes procedure is feasible, allowing right ventricle rehabilitation and restoring a biventricular physiology.
\end{abstract}

See Commentaries on pages 284,286 , and 288 .

At 17 months, she underwent tricuspid valve cone repair and pulmonary

Patient 2 was a 3.3-kg full-term neonate who needed ECMO support soon after birth due to tachyarrhythmia and low cardiac output. At 4 days of life, she underwent a Starnes procedure. Left bronchomalacia and left lower pulmonary vein stenosis complicated her recovery, necessitating mechanical ventilation and tracheostomy. At 5 months, heart catheterization revealed a mean pulmonary artery pressure of $21 \mathrm{~mm} \mathrm{Hg}$, elevated left ventricular end-diastolic pressure $(15 \mathrm{~mm} \mathrm{Hg})$, and $42 /$ $8 \mathrm{~mm} \mathrm{Hg}$ right ventricular (RV) pressures. This condition, combined with the pulmonary problems and mechanical ventilation dependency, contraindicated a Glenn procedure. Owing to episodes of hypoxemia, she underwent a cone repair, pulmonary valvuloplasty, left lower pulmonary vein repair, and ablation of the atrial reentry circuits.

\section{Operative Technique}

Both operations were performed using bicaval cannulation, moderate hypothermia, and cold blood cardioplegia. The Ebstein's valve malformations were repaired using the cone procedure (Figure 1), as detailed elsewhere. ${ }^{4}$ The well-developed pulmonary valve in patient 1 required additional commissurotomy and polytetrafluoroethylene patch reconstruction of a torn leaflet (Video 1). The hypoplastic pulmonary valve in patient 2 was repaired by commissurotomy and monocusp polytetrafluoroethylene patch enlargement. In both patients, the atrial septal defect was partially closed with a fenestrated patch. 

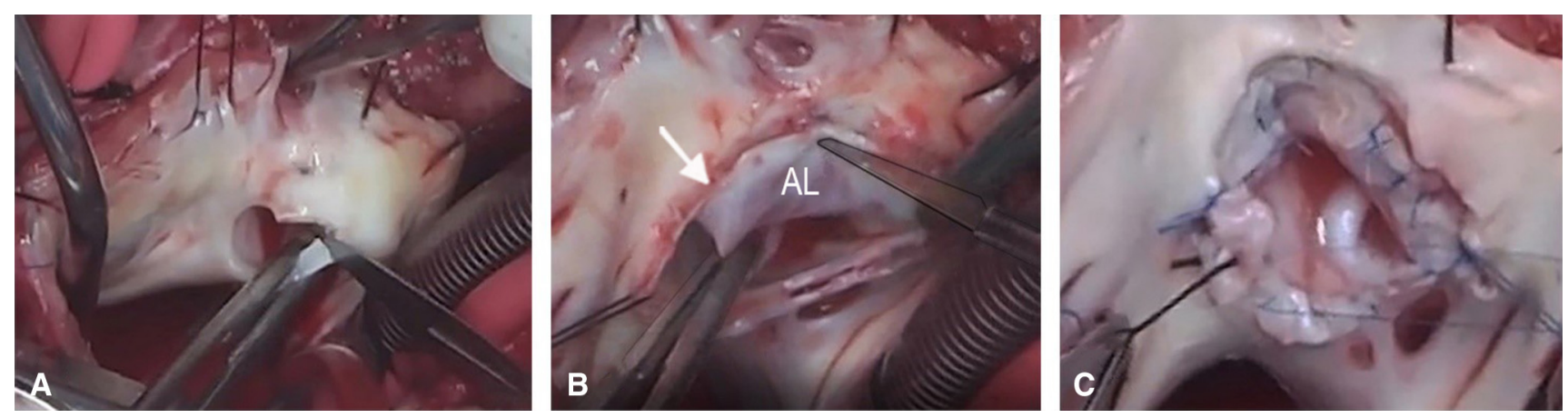

FIGURE 1. Da Silva cone procedure. A, Removal of the fenestrated polytetrafluoroethylene patch, with care taken to avoid damaging the anterior leaflet, which is adjacent to the patch. B, Extensive tricuspid valve mobilization initiated at the anterior leaflet hinge line and continued clockwise toward the inferior leaflet. A second incision was made near the anteroseptal commissure (arrow), counterclockwise, to mobilize the medial part of the anterior leaflet $(A L)$ and the entire septal leaflet from their proximal attachments. C, Two vertical interrupted sutures unite the medial and lateral aspects of the septal leaflet with the anterior and inferior leaflets, respectively. The resulting cone-shaped structure is sutured to the anatomic tricuspid valve annulus, completing the cone repair.

\section{RESULTS}

Both patients had excellent hemodynamic results at discharge, with oxygen saturation levels $>92 \%$ in room air. The hospital discharge echocardiograms showed that patient 1 had trivial tricuspid regurgitation, mild pulmonic valve insufficiency, and mild RV dysfunction. Patient 2 had mild tricuspid regurgitation, severe pulmonary insufficiency, and moderate RV dysfunction. Figure 2 shows the

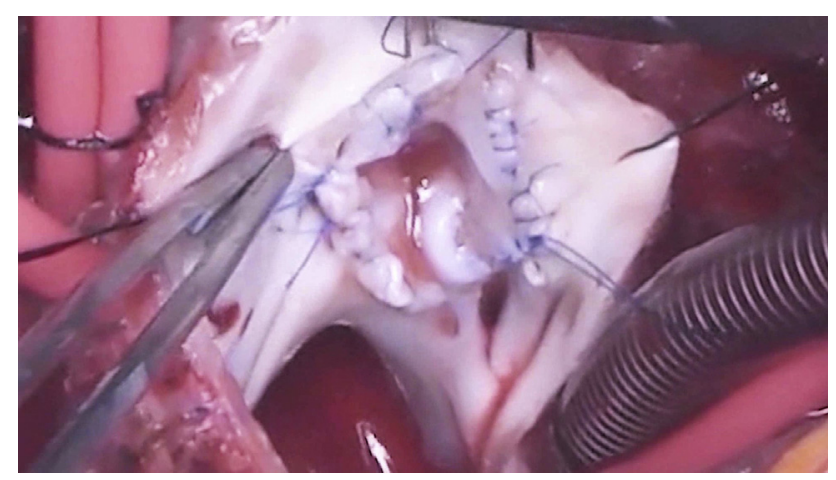

VIDEO 1. Da Silva cone repair of the tricuspid valve in a 17 -month-old child who underwent a previous Starnes procedure as a neonate, followed by a Glenn procedure and pulmonary valvotomy at 4 months. The patient's initial diagnosis was Ebstein's anomaly with pulmonary atresia. The sequence is as follows: (1) removal of the right ventricle exclusion patch, mobilization of the abnormally attached tricuspid valve leaflets, and construction of a cone-shaped structure using the leaflet tissues and a piece of fresh autologous pericardium to enlarge the septal leaflet; (2) valve reattachment to the normal atrioventricular junction without reduction of the tricuspid valve annulus; (3) pulmonary valve repair using a path to reconstruct the torn anterior pulmonary valve leaflet; (4) preoperative and postoperative echocardiograms. Video available at: https://www.jtcvs.org/ article/S2666-2507(20)30232-7/fulltext. morphological changes in the right ventricle over time for both patients.

\section{DISCUSSION}

Neonates with severe EA palliated with the Starnes procedure usually follow the single-ventricle repair pathway. Although usually successful, this approach excludes the right ventricle from the pulmonary circulation, which dooms the patients to the potential long-term complications of single-ventricle physiology.

Here we demonstrated that it is possible to rehabilitate the right ventricle after the Starnes procedure in patients with EA and pulmonary atresia. In theory, the 1-1/2 repair has low risk when performed after the Glenn procedure, as in patient 1 . We recommend this procedure to all patients with sufficient tricuspid valve tissue approximately 6 months after the Glenn procedure, when mature lungs and a well-developed pulmonary artery demand less RV performance for a successful outcome. We consider a direct 2-ventricle repair in selected patients who are poor candidates for a Glenn procedure. Fortunately, the right ventricle undergoes a progressive reverse remodeling process after the Starnes procedure. ${ }^{5}$ At some point, it may become a capable pump, permitting the repair. Patient 2 achieved an adequate situation at 5 months; his RV systolic pressure was $42 \mathrm{~mm} \mathrm{Hg}$ at the heart catheterization. In both situations, leaving an atrial septal fenestration appears to be important to compensate for possible early postoperative RV dysfunction.

Encouraged by these initial results, we envision that the efficacy of the neonatal Starnes procedure and the feasibility of RV rehabilitation after that procedure favor this staged repair over primary 2-ventricle repair in selected critical newborns with EA.

In conclusion, the $\mathrm{Da}$ Silva cone operation appears to be a viable alternative for repairing EA after an initial neonatal 

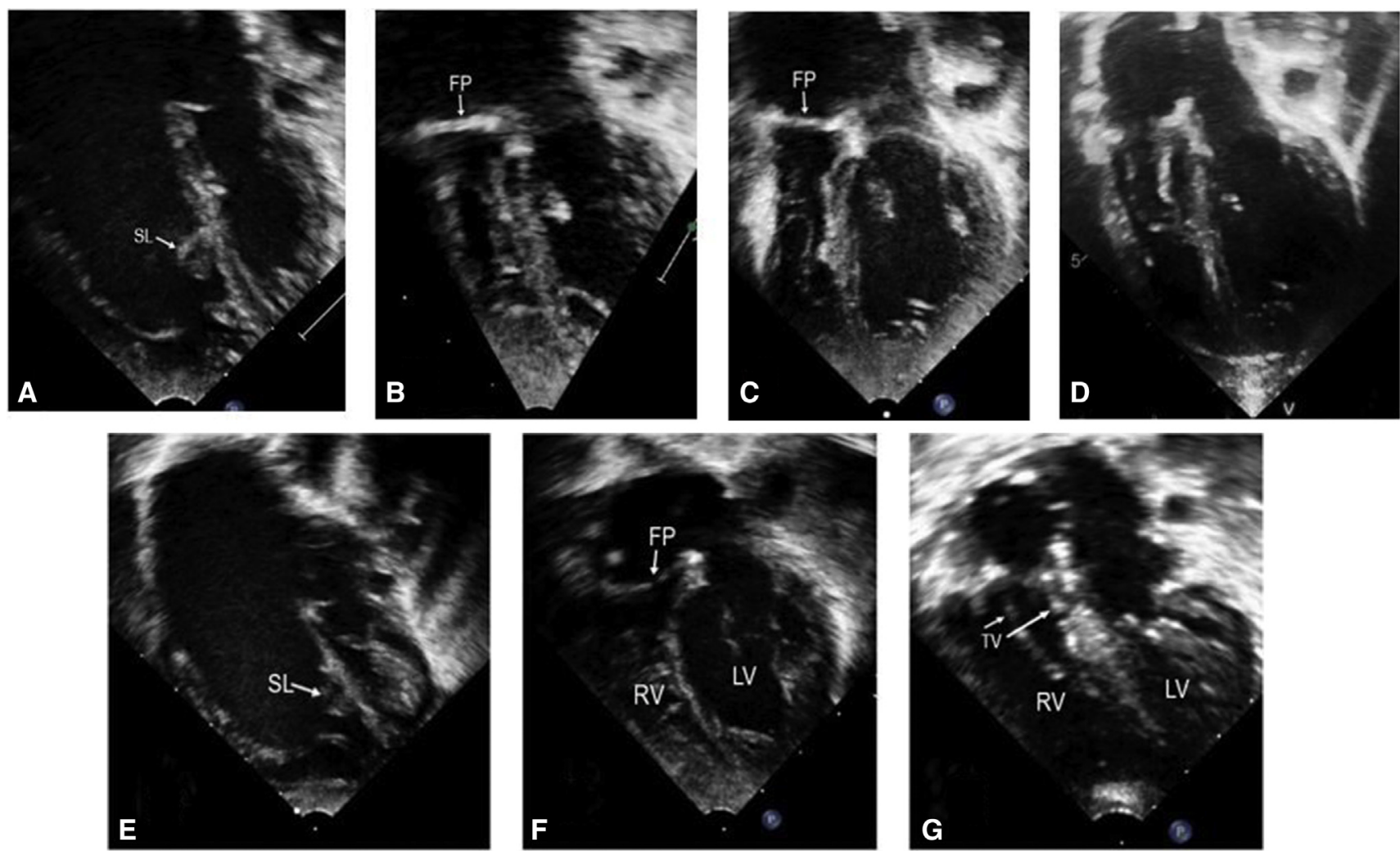

FIGURE 2. Sequential echocardiograms in patient 1 (A-D) and patient 2 (E-G). A, Severe Ebstein's anomaly (EA) with septal and inferior leaflet displacement and dilated right cardiac chambers. B, Small pre-Glenn right ventricle. C, Larger right ventricle after the Glenn procedure and pulmonary valvotomy. D, Right ventricle after the cone procedure. E, Severe EA with dilated right cardiac chambers. F, Small, underfilled right ventricle and well-expanded left ventricle after the Starnes procedure. G, Good-sized right ventricle and well-positioned tricuspid valve after the cone repair and atrial septal defect closure with a fenestrated patch. $S L$, Septal leaflet; $F P$, fenestrated patch; $R V$, right ventricle; $L V$, left ventricle; $T V$, tricuspid valve.

Starnes procedure. Further studies are needed to confirm the theoretical benefits of this strategy over the single-ventricle pathway.

\section{References}

1. Starnes VA, Pitlick PT, Bernstein D, Griffin ML, Choy M, Shumway NE. Ebstein's anomaly appearing in the neonate: a new surgical approach. $J$ Thorac Cardiovasc Surg. 1991;101:1082-7.
2. Reemtsen BL, Fagan BT, Wells WJ, Starnes VA. Current surgical therapy for Ebstein's anomaly in neonates. J Thorac Cardiovasc Surg. 2006;132:1285-90.

3. Kumar SR, Kung G, Noh N, Castillo N, Fagan B, Wells WJ, et al. Single-ventricle outcomes after neonatal palliation of severe Ebstein anomaly with modified Starnes procedure. Circulation. 2016;134:1257-64.

4. da Silva JP, da Silva LF. Ebstein's anomaly of the tricuspid valve: the cone repair Semin Thorac Cardiovasc Surg Pediatr Card Surg Annu. 2012;15:38-45.

5. Reemtsen BL, Polimenakos AC, Fagan BT, Wells WJ, Starnes VA. Fate of the right ventricle after fenestrated right ventricular exclusion for severe neonatal Ebstein anomaly. J Thorac Cardiovasc Surg. 2007;134:1406-10. 